\title{
Risk factors for benign prostatic enlargement: The role of lifestyle habits at younger age. The \#Controllati2017 initiative study group
}

\author{
Vincenzo Mirone ${ }^{1}$, Giuseppe Carrieri ${ }^{2}$, Giuseppe Morgia $^{3}$, Luca Carmignani ${ }^{4}$, Giuseppe Vespasiani ${ }^{5}$, \\ Fabio Parazzini ${ }^{6}$, Walter Artibani ${ }^{7}$ \\ ${ }^{1}$ Università degli Studi di Napoli Federico II, UOC di Urologia della A.O.U. Federico II Napoli, Italy; \\ ${ }^{2}$ Dipartimento Nefro/Urologico Clinica Urologica e Centro Trapianti di Rene, Università degli Studi di Foggia, Italy; \\ ${ }^{3}$ Università degli Studi di Catania Presidio Ospedaliero Policlinico, Catania, Italy; \\ ${ }^{4}$ Università degli Studi di Milano, Divisione Universitaria di Urologia, IRCCS Policlinico San Donato Milano, Italy; \\ ${ }^{5}$ UOC Urologia, Fondazione PTV - Policlinico Tor Vergata, Roma, Italy; \\ ${ }^{6}$ Università degli Studi di Milano Dipartimento di Scienze Cliniche e di Comunità, IRCCS Policlinico, Milano, Italy; \\ ${ }^{7}$ Azienda Ospedaliera Universitaria Integrata, Verona, Italy.
}

\begin{abstract}
Summary Objective: The risk factors for benign prostatic enlargement (BPE) are not well understood and particularly few data are available from Italian population.

Materials and methods: This was an observational cross sectional study aimed to examine the association between several risk factors and BPE. During the "\#Controllati2017" initiative, men aged 18 years or more were invited to attend participating urologic centers for a free of charge visit for counseling about urologic or andrologic conditions. Each participating man underwent a physical examination including digital rectal examination (DRE). Further he was asked about his medical history, urologic symptoms, sexual activity and related problems. Diagnosis of BPE was made by the urologist after DRE.

Results: Out of the 1902 [mean age 54 years (SD 12, range 18-92)] considered men, a total of 603 subjects (31.7\%) had diagnosis of BPE. The diagnosis of BPE increased from 9.3\% in men aged $<=50$ years, to $34.1 \%$ in those aged $51-60$ years and to $58.7 \%$ among men aged $>60$ years. A history of hypertension, diabetes, heart diseases, hypercholesterolemia and hypertriglyceridemia were all significantly associated with an increased risk of BPE in the total series and, although not always in a statistically significant way, in strata of age. Physical activity (PA) was significantly associated with a decreased risk of BPE. We have further analyzed the risk of BPE in men with one or more of the identified risk factors (i.e. hypertension, diabetes, heart disease, hypercholesterolemia, hypertriglyceridemia and low PA): the risk of $B P E$ increased with number of risk factors reported by the subjects. The estimated risk were higher among younger men.

Conclusion: In our study a history of hypertension, diabetes, heart disease, hypercholesterolemia and hypertriglyc-

eridemia increased the risk and physical activity lowered the risk of BPE. This risk profile was observed also in men aged $<50$ years.
\end{abstract}

KEY WORDS: Benign prostatic enlargement (BPE); Hypertension; Diabetes; Hearth disease; Hypercholesterolemia;

Hypertriglyceridemia; Physical activity.

Submitted 29 November 2017; Accepted 8 December 2017

\section{INTRODUCTION}

Despite the high prevalence of the conditions, the risk factors for benign prostatic hyperplasia (BPH) or benign prostatic enlargement (BPE) are not well understood.

Some studies have suggested a role of diabetes or hypertension in the pathogenesis of PBH (1).

Further, HDL-cholesterol levels were an independent predictors of prostate enlargement (2). Other studies have shown that body mass index and waist circumference were positively related with prostate volume $(3,4)$. All these factors are associated with metabolic syndrome, a condition that increase the risk of cardiovascular diseases (5).

Further, it has been suggested that regular physical activity (PA) may decreased the risk of BPE (6).

These findings suggest that healthy life habits may lower the risk of growth of prostatic volume.

Available data on the role of these factors are scanty and particularly few data are available from Italian population.

In June 2017, the Italian Society of Urology conducted the "\#Controllati2017" preventive initiative. In the framework of this preventive campaign, data have been collected on determinants of the risk of BPE.

\section{Materials AND Methods}

This was an observational cross sectional study aimed to examine the association between several risk factors and BPE.

During the "\#Controllati2017" ( $1^{\text {st }}$ June-15 $15^{\text {th }}$ July 2017) initiative, males of any age were offered to attend a free of charge visit for counseling about urologic or andrologic conditions in urological centers affiliated to the Italian Society of Urology (Società Italiana di Urologia). A pamphlet inviting men for a free of charge check-up and listing participating centers was left in chemists and general practitioners' waiting rooms; an advertising campaign was set in the press and broadcast media.

Each participating man underwent a physical examination including digital rectal examination (DRE) and was 
asked by the urologist about his medical history, urologic symptoms, sexual activity and related problems.

A total of 173 centers participated to the initiative. Epidemiological data were collected in 61 centers for a total of 2572 men who filled the questionnaire.

Data were recorded with a simple questionnaire used by all centers.

The first section, about age and life habits was completed by the patient. History of hypertension, diabetes, hearth diseases and other medical conditions, and the findings of the clinical examination were recorded by the urologist.

Diagnosis of BPE was made by the urologist after DRE.

Erectile dysfunction (ED) was diagnosed according to the definition of the NIH Consensus Development Panel (7).

The 2002 International Continence Society definitions were used for frequency, nicturia, urgency, dysuria (intermittency, slow stream, straining, terminal dribble, postmicturition dribble) incomplete emptying (8).
The section on PA included questions on self reported intensity of activity at work and in leisure time separately. Patients were asked about their PA, which were classified into five categories (scores between 1 and 5) corresponding to 'very heavy', 'heavy', 'average', 'moderate' and 'light'. The scores of the two highest levels of occupational and leisure PA were combined, in order to obtain adequate numbers in the categories.

For the purpose of the present paper we compared the characteristics of subjects with and without BPE.

Mean (standard deviation, SD), median (range) or frequency (percent,\%) were computed as appropriate.

Odds ratios (OR), and the corresponding 95\% confidence intervals (CI), were derived using unconditional multiple logistic regression, fitted by the method of maximum likelihood, in which the dependent variable was the presence (case) or absence (control) of BPE and the independent ones were the exposures considered in the analysis. We included in the model potential co-variates

\section{Table 1.}

Distribution of 603 subjects with and 1299 without benign prostatic enlargement according to selected factors and strata of age.

\begin{tabular}{|c|c|c|c|c|c|c|c|c|c|c|}
\hline & \multicolumn{3}{|c|}{$\leq 50$ years } & \multicolumn{3}{|c|}{$51-60$ years } & \multicolumn{3}{|c|}{$\geq 61$ years } & \multirow[b]{2}{*}{$\begin{array}{l}\text { Total series } \\
\text { OR ( } 95 \% \mathrm{Cl})\end{array}$} \\
\hline & $\begin{array}{c}\text { No BPE } \\
N=681 \\
(90.7) \\
\end{array}$ & $\begin{array}{c}\text { BPE } \\
N=70 \\
(9.3) \\
\end{array}$ & $\begin{array}{l}\text { adj OR } \\
(95 \% \mathrm{Cl})\end{array}$ & $\begin{array}{c}\text { No BPE } \\
N=382 \\
(65.9) \\
\end{array}$ & $\begin{array}{c}\text { BPE } \\
N=198 \\
(34.1) \\
\end{array}$ & $\begin{array}{c}\text { adj OR } \\
\text { (95\% Cl) }\end{array}$ & $\begin{array}{c}\text { No BPE } \\
N=236 \\
(41.3) \\
\end{array}$ & $\begin{array}{c}\text { BPE } \\
N=335 \\
(58.7)\end{array}$ & $\begin{array}{c}\text { adj OR } \\
\text { (95\% Cl) }\end{array}$ & \\
\hline \multicolumn{11}{|l|}{ BMI $\left(\mathrm{kg} / \mathrm{m}^{2}\right)$} \\
\hline$<25$ & $340(50.9)^{*}$ & $35(50.7)$ & 1 & 154 (41.1) & 61 (31.6) & 1 & $87(37.3)$ & $116(35.4)$ & 1 & 1 \\
\hline$\geq 25-<30$ & $254(38.0)$ & 25 (36.2) & $1.0(0.6-1.6)$ & $168(44.8)$ & 95 (49.2) & $1.4(1.0-2.1)$ & $117(50.2)$ & $152(46.3)$ & $1.0(0.7-1.9)$ & $1.4(1.1-1.7)$ \\
\hline$\geq 30$ & 74 (11.1) & $9(10.8)$ & $1.2(0.5-2.6)$ & 53 (14.1) & 37 (19.2) & $1.2(0.6-2.2)$ & $29(12.4)$ & 60 (18.3) & $1.55(0.9-2.6)$ & $1.9(1.4-2.5)$ \\
\hline \multicolumn{11}{|l|}{ Smoking habits } \\
\hline Never smokers & 391 (58.1) & $34(48.6)$ & 1 & $195(51.3)$ & 87 (43.9) & 1 & $102(43.8)$ & $140(42.3)$ & 1 & 1 \\
\hline Ever smokers & 282 (41.9) & $36(51.4)$ & $1.5(0.8-2.7)$ & $185(48.6)$ & 111 (56.1) & $1.3(0.8-2.0)$ & 131 (56.2.) & $191(57.7)$ & $1.1(0.7-1.7)$ & $1.4(0-9-1.8)$ \\
\hline \multicolumn{11}{|l|}{ Occupational PA } \\
\hline No & $122(18.9)$ & $13(21.0)$ & 1 & 77 (21.9) & 36 (19.6) & 1 & $43(22.3)$ & $73(28.2)$ & 1 & 1 \\
\hline Low & 203 (31.4) & $20(32.3)$ & $0.9(0.4-1.9)$ & $112(31.9)$ & $56(30.4)$ & $1.1(0.7-1.8)$ & $54(28.0)$ & $82(31.7)$ & $0.9(0.5-1.9)$ & $0.9(0.6-1.1)$ \\
\hline Moderate & $193(29.8)$ & 23 (37.1) & $1.1(0.6-2.3)$ & $108(30.8)$ & $62(33.7)$ & $1.2(0.7-2.0)$ & 79 (40.9) & $80(30.9)$ & $0.6(0.4-1.0)$ & $0.8(0.7-1.1)$ \\
\hline Intense & $129(19.9)$ & $6(9.7)$ & $0.4(0.2-1.2)$ & $54(15.4)$ & $30(16.3)$ & $1.2(0.7-2.2)$ & $17(8.8)$ & $24(9.3)$ & $0.8(0.4-1.7)$ & $0.6(0.4-0.9)$ \\
\hline \multicolumn{11}{|l|}{ Leisure PA } \\
\hline No & $61(9.1)$ & $5(7.9)$ & 1 & 40 (11.0) & 30 (16.2) & 1 & $27(12.3)$ & 41 (12.9) & 1 & 1 \\
\hline Low & $195(29.2)$ & $20(31.8)$ & $1.3(05-3.5)$ & $115(31.7)$ & $51(27.6)$ & $0.6(0.3-1.1)$ & $62(28.2)$ & $90(28.4)$ & $1.0(0.5-1.7)$ & $0.7(0.5-1.0)$ \\
\hline Moderate & $285(42.6)$ & $29(46.0)$ & $1.2(0.5-3.3)$ & $157(43.2)$ & $70(37.8)$ & $0.6(0.3-1.0)$ & 97 (44.1) & $152(48.0)$ & $1.0(0.6-1.8)$ & $0.8(0.6-1.1)$ \\
\hline Intense & $128(19.1)$ & $9(14.3)$ & $0.9(0.3-2.8)$ & $51(14.0)$ & $34(18.4)$ & $0.9(0.5-1.7)$ & $34(15.4)$ & $34(10.7)$ & $0.7(0.3-1.3)$ & $0.6(0.4-0.9)$ \\
\hline \multicolumn{11}{|l|}{ Hypertension } \\
\hline No & $595(90.6)$ & $50(76.9)$ & 1 & $256(70.0)$ & $106(56.7)$ & 1 & $118(51.8)$ & $150(45.7)$ & 1 & 1 \\
\hline Yes & $62(9.4)$ & $15(23.1)$ & $2.9(1.5-5.4)$ & $110(30.0)$ & 81 (43.3) & $1.8(1.2-2.6)$ & $110(48.2)$ & $178(54.3)$ & $1.2(0.9-1.8)$ & $3.1(2.5-3.8)$ \\
\hline \multicolumn{11}{|l|}{ Diabetes } \\
\hline No & $652(99.2)$ & $62(98.4)$ & 1 & $341(95.0)$ & $164(90.6)$ & 1 & $198(89.2)$ & $266(83.4)$ & 1 & 1 \\
\hline Yes & $5(0.8)$ & $1(1.6)$ & $2.1(0.2-18.3)$ & $18(5.0)$ & $17(9.4)$ & $2.0(1.0-3.9)$ & $24(10.8)$ & $53(16.6)$ & $1.6(0.9-2.8)$ & $3.7(2.5-5.4)$ \\
\hline \multicolumn{11}{|l|}{ Hearth disease } \\
\hline No & $650(99.1)$ & $61(96.8)$ & 1 & 332 (93.3) & 164 (91.1) & 1 & $189(87.5)$ & $245(79.8)$ & 1 & 1 \\
\hline Yes & $6(0.9)$ & $2(3.2)$ & $3.6(0.7-18.0)$ & $24(6.7)$ & $16(8.9)$ & $1.2(0.7-2.6)$ & $27(12.5)$ & $62(20.2)$ & $1.8(1.1-2.9)$ & $3.5(2.5-5.0)$ \\
\hline \multicolumn{11}{|c|}{ Hypertriglyceridaemia } \\
\hline No & $601(91.9)$ & $57(87.7)$ & 1 & $302(86.0)$ & $152(85.4)$ & 1 & $181(85.8)$ & $257(84.3)$ & 1 & 1 \\
\hline Yes & $53(8.1)$ & $8(12.3)$ & $1.6(0.7-3.5)$ & $49(14.0)$ & $26(14.6)$ & $1.1(0.6-1.8)$ & 30 (14.2) & $48(15.7)$ & $1.1(0.7-1.9)$ & 1.4 (1.1-1.9) \\
\hline \multicolumn{11}{|c|}{ Hypercholesterolaemia } \\
\hline No & 533 (81.0) & $49(74.2)$ & 1 & $263(73.9)$ & $122(67.4)$ & 1 & $157(71.7)$ & $212(68.0)$ & 1 & 1 \\
\hline Yes & $125(19.0)$ & $17(25.8)$ & $1.5(0.8-2.7)$ & $93(26.1)$ & $59(32.6)$ & $1.4(0.9-2.0)$ & $62(28.3)$ & $100(32.0)$ & $1.2(0.8-1.7)$ & $1.6(1.3-2.0)$ \\
\hline
\end{tabular}


considered as categorical variables. The terms included in the model were those found statistically significantly associated with the risk of BPE in the crude analysis. Further, we computed an overall risk score including all factors found statistically significantly associated with the risk of BPE in the crude analysis of the total series. Subjects were classified according the presence of none, 1,23 or more factor and corresponding OR were computed.

\section{RESULTS}

Overall, 2572 men were observed in 61 participating centers: the mean number of attending men per center was 42 (median 35, range 4-126). Their mean age was 54 years [standard deviation (SD) 12, range 18-92].

After exclusion of men who did not filled the demographic questionnaire and those who underwent previous partial and complete prostatectomy, we analyzed data from 1902 men, aged 54 years (SD 12, range 1892). The reason for the visit was urinary symptoms in $318(16.7 \%)$, sexual problems in $234(12.3 \%)$, renal disease in $37(2.0 \%)$ and prostatic problems in 346 (18.2\%). Prevention was the only reason for consultation in 1156 subjects $(60.8 \%$, each man could indicate one reason or more).

Out of the 1902 considered men, a total of 603 subjects jects according to the diagnosis of BPE according to class age are shown in Table 1.

A history of hypertension, diabetes, hearth disease, hypercholesterolemia and hypertriglyceridemia were all significantly associated with an increased BPE risk in the total series and, although not always in a statistically significant way, in all the three considered strata of age. PA was significantly associated with a decreased risk of BPE.

We have further analyzed the risk of BPE in men with one or more of the identified risk factors (i.e. hypertension, diabetes, hearth disease, hypercholesterolemia and hypertriglyceridemia and PA): the risk of BPE increased with number of risk factors reported by the subjects. The estimated OR were higher among younger men (Table 2).

Table 3 considers the frequency of urinary symptoms among men with a diagnosis of BPE in strata of age.

The frequency of all symptoms increased with age and dysuria was the most common symptoms at all ages.

Considering subjects for which the information was available, ED was reported in the 39,8\% (225/565) of men with BPE and 16.3\% (201/1235) of those without BPE (adj chi suare $\mathrm{p}<0.05$ ). This difference in the frequency of DE was consistent in the three considered strata of age: in particular considering men aged $<50$ years the frequency of ED was $17.5 \%(11 / 63)$ among the men with BPE and 9.9\% (64/644) among those without BPE (adj chi square $=0.06$ ).

Table 2.

Association between benign prostatic enlargement (BPE) and number of risk factors.

\begin{tabular}{|c|c|c|c|c|c|c|c|c|c|c|}
\hline & \multicolumn{3}{|c|}{$\leq 50$ years } & \multicolumn{3}{|c|}{$51-60$ years } & \multicolumn{3}{|c|}{$\geq 61$ years } & \multirow{2}{*}{$\begin{array}{c}\text { Total series } \\
\text { adj OR } \\
(95 \% \mathrm{Cl})\end{array}$} \\
\hline & $\begin{array}{c}\text { No BPE } \\
\mathrm{N}=681 \\
(90.7)\end{array}$ & $\begin{array}{c}\text { BPE } \\
N=70 \\
(9.3)\end{array}$ & $\begin{array}{l}\text { adj OR } \\
(95 \% \text { Cl) }\end{array}$ & $\begin{array}{c}\text { No BPE } \\
N=382 \\
(65.9)\end{array}$ & $\begin{array}{c}\text { BPE } \\
N=198 \\
(34.1)\end{array}$ & $\begin{array}{l}\text { adj OR } \\
(95 \% \mathrm{Cl})\end{array}$ & $\begin{array}{c}\text { No BPE } \\
N=236 \\
(41.3)\end{array}$ & $\begin{array}{c}\text { BPE } \\
N=335 \\
(58.7)\end{array}$ & $\begin{array}{l}\text { adj OR } \\
(95 \% \mathrm{Cl})\end{array}$ & \\
\hline \multicolumn{11}{|c|}{$\begin{array}{l}\text { Number of risk factors } \\
\text { reported by the subject }\end{array}$} \\
\hline 0 & $494(72.5)$ & $42(60.0)$ & 1 & $187(49.0)$ & $72(36.4)$ & 1 & $82(34.8)$ & 95 (28.4) & 1 & 1 \\
\hline 1 & $134(19.7)$ & $17(24.3)$ & $1.8(0.8-3.3)$ & $122(31.9)$ & $75(37.9)$ & $1.7(1.1-2.6)$ & 81 (34.3) & 105 (31.3) & $0.9(0.6-1.6)$ & $1.3(1.0-1.8)$ \\
\hline 2 & $38(5.6)$ & $7(10.0)$ & $2.3(0.8-6.7)$ & 44 (11.5) & 31 (15.7) & $1.9(1.0-3.4)$ & $43(18.2)$ & $78(23.4)$ & $1.1(0.6-1.9)$ & $1.5(1.0-2.2)$ \\
\hline$\geq 3$ & $15(2.2)$ & $4(5.7)$ & $3.5(1.0-11.6)$ & $29(7.6)$ & $20(10.1)$ & $2.0(1.0-4.1)$ & 30 (12.7) & $57(17.0)$ & $1.9(1.0-3.7)$ & $2.1(1.4-3.3)$ \\
\hline
\end{tabular}

Table 3.

Association between benign prostatic enlargement (BPE) and urinary symptoms.

\begin{tabular}{|c|c|c|c|c|c|c|}
\hline & \multicolumn{2}{|c|}{$\leq 50$ years } & \multicolumn{2}{|c|}{$51-60$ years } & \multicolumn{2}{|c|}{$\geq 61$ years } \\
\hline & No BPE & BPE & No BPE & BPE & No BPE & BPE \\
\hline & No. (\%) & No. (\%) & №. (\%) & No. (\%) & No. (\%) & No. (\%) \\
\hline Urgency & $96(14.1)^{*}$ & 10 (14.3) & $28(7.3)$ & $32(16.2)$ & $11(4.7)$ & $52(15.5)$ \\
\hline Nicturia & $52(7.6)$ & 17 (24.3) & $47(12.3)$ & $61(30.8)$ & $33(14.0)$ & 115 (34.3) \\
\hline Dysuria & 86 (12.6) & 38 (51.4) & $92(24.1)$ & $108(54.5)$ & 74 (31.4) & 212 (63.3) \\
\hline Frequency & $46(6.8)$ & $27(38.6)$ & 48 (12.7) & 79 (39.9) & $24(10.2)$ & 131 (39.1) \\
\hline Incomplete voiding sensation & $70(10.3)$ & $32(45.7)$ & 54 (14.1) & $80(40.4)$ & $26(11.0)$ & $142(42.4)$ \\
\hline
\end{tabular}

\section{Discussion}

The general results of this analysis show that a history of hypertension, diabetes, hearth disease, hypercholesterolemia and hypertriglyceridemia increase the risk of BPE at all ages.

A regular PA tended to decrease the risk. Interestingly these factors were associated with PBE risk also in men aged 50 years or less, thus underlining the role of a healthy life style among younger men.

(31.7\%) had diagnosis of BPE. The diagnosis of BPE increased from $9.3 \%$ in men aged $<=50$ years, to $34.1 \%$ in those aged $51-60$ years and to $58.7 \%$ among men aged $>60$ years. The general characteristics of study sub-
This suggestion was also confirmed when we have considered the risk BPE among men with one, two or three of the factors found associated with the risk of PBE: the presence of more risk factors was more markedly associ- 
ated with the risk of BPE in men aged 50 years or less. The role of modifiable lifestyle factors on the risk of $\mathrm{BPH}$ has been widely suggested (9). For example, a review of the literature conducted in the late 2000 and including eight studies has shown, compared to the sedentary group, a pooled odds ratios for BPH or LUTS of 0.70 (95\% CI 0.44-1.13, $\mathrm{p}=0.14$ ), 0.74 (95\% CI 0.60-0.92, $\mathrm{p}=0.005)$, and $0.74(95 \% \mathrm{CI} 0.59-0.92, \mathrm{p}=0.006)$ for men engaging in light, moderate, and heavy physical activity, respectively (6). We confirm these findings, in particular the protective effects of PA was more evident among younger men.

Obesity, elevated fasting plasma glucose, diabetes, dyslipidemia, and the metabolic syndrome may all significantly increase the risks of BPH and low urinary tract symptoms (10-12). In our study diabetes, hypercholesterolemia, hypertrigliceridemia were associated with an increased risk of BPE. Further a history of hypertension and hearth diseases increased the risk. All these findings underline that BPE shares similar risk factor with metabolic syndrome and cardiovascular diseases.

The biological link between these risk factors and the prostatic growth is not completely understood.

However, for example, it has been shown that lipids (oxidized low-density lipoprotein, LDL) increase in vitro the secretion of growth and pro-inflammatory factors by human stromal BPH cells in culture (13). Along this line in a clinical perspective, the addition of statins to standard therapy for BHP lowered prostate volume (14).

It has been suggested that metabolic syndrome-dependent prostate growth may play a major role among older men (15). An interesting findings of the present study is the observation that the OR of BPE associated with the presence of several risk factors such as PA and hyperlipidemia, diabetes and hypertension were higher (although no statistically significantly different) among younger than older men. This findings underline the role of encouraging healthy lifestyle habits among men under the 50 years of age in order to reduce the risk of $\mathrm{BPH}$.

\section{Limits}

As previously discussed in the paper reporting the results of the \#Controllati2016 initiative (16), the major flaw of this study is the fact that the study population were men voluntarily presenting to the participating centers and physicians associated to the Italian Society of Urology (SIU). Along this line the observed frequency of BPE in this population, about $30 \%$, is higher than reported in the literature (17).

Further, the participating centers were not randomly identified among all members, so they cannot be considered representative of all Italian centers. However, they were well distributed over the main areas of the country and there were no marked differences in the results among centers in various large Italian areas, giving strong support to the consistency of the general results. Likewise, the prevalence of hypertension and diabetes and overweight were largely similar to the general Italian population.

For example the percentage of hypertensive subjects was largely consistent with that of the Italian population (18) and with the results of the \#Controllati2016 survey (16).
In any case, any inference from the present analysis must be made in strictly comparative terms and strictly referred to men attending urologic services.

The diagnosis of BPE was based on DRE that tends to underestimate the prostatic volume (17). In any case any misclassification of men with or without BPE should lower the observed associations.

The strengths of the study included the fact that it provides information from a large series of men identified in all parts of Italy. Further, the participation rate was very high. Along this line, the patients presented themselves voluntarily to the physician, so their answers to all questions should be truthful.

\section{Conclusions}

In our study a history of hypertension, diabetes, hearth disease, hypercholesterolemia and hypertriglyceridemia increased the risk and physical activity lower the risks of BPE.

These findings are consistent with other studies. The findings suggest that BPE risk is associated with lifestyle habits and modifiable risk factors of cardiovascular disease. Cohort studies are needed to evaluate if modification of lifestyle habits may change the natural history of $\mathrm{BPH}$.

\section{ACKNOWLEDGEMENT}

The \#Controllati2017 initiative was partially supported by an unconditional grant of Menarini.

\section{REFERENCES}

1. Bourke JB, Griffin JP. Hypertension, diabetes mellitus, and blood groups in benign prostatic hypertrophy. Br J Urol. 1966; 38:18-23.

2. Nandeesha $H$, Koner BC, Dorairajan LN, Sen SK. Hyperinsulinemia and dyslipidemia in non-diabetic benign prostatic hyperplasia. Clin Chim Acta. 2006; 370:89-93.

3. Lee S, Min HG, Choi SH, et al. Central obesity as a risk factor for prostatic hyperplasia. Obesity (Silver Spring) 2006; 14:172-9.

4. Muller RL, Gerber L, Moreira DM, et al. Obesity is associated with increased prostate growth and attenuated prostate volume reduction by dutasteride. Eur Urol. 2013; 63:1115-21.

5. Ford ES. Risks for all-cause mortality, cardiovascular disease, and diabetes associated with the metabolic syndrome: a summary of the evidence. Diabetes Care. 2005; 28:1769-78.

6. Parsons JK, Kashefi C. Physical activity, benign prostatic hyperplasia, and lower urinary tract symptoms Eur Urol. 2008; 53:1228-35

7. NIH Consensus Conference (1993) Impotence. Consensus Development Panel on Impotence. JAMA 1993; 270:83-90.

8. Abrams P, Cardozo L, Fall M, et al. The standardization of terminology of lower urinary tract function: report from the Standardisation Sub-committee of the International Continence Society. Neurourol Urodyn. 2002; 21:167-78.

9. Raheem OA, Parsons JK. Associations of obesity, physical activity and diet with benign prostatic hyperplasia and lower urinary tract symptoms. Curr Opin Urol. 2014; 24:10-4.

10. Parsons JK, Carter HB, Partin AW, et al. Metabolic factors asso- 
ciated with benign prostatic hyperplasia. J Clin Endocrinol Metab. 2006; 91:2562-8.

11. Kristal AR, Arnold KB, Schenk JM, et al. Racelethnicity, obesity, health related behaviors and the risk of symptomatic benign prostatic hyperplasia: results from the prostate cancer prevention trial. J Urol. 2007; 177:1395-400.

12. Gupta A, Gupta S, Pavuk M, Roehrborn CG. Anthropometric and metabolic factors and risk of benign prostatic hyperplasia: a prospective cohort study of Air Force veterans. Urology 2006; 68:1198-205; Parsons JK. Modifiable risk factors for benign prostatic hyperplasia and lower urinary tract symptoms: new approaches to old problems. J Urol. 2007; 178:395-401.

13. Vignozzi L, Gacci M, Cellai I, et al. Fatboosts, while androgen receptor activation counteracts, $\mathrm{BPH}$-associated prostate inflammation. Prostate. 2013; 73:789-800
14. Lee SH, Park TJ, Bae MH, et al. Impact of treatment with statins on prostate-specific antigen and prostate volume in patients with benign prostatic hyperplasia. Korean J Urol. 2013; 54:750-5.

15. Gacci M, Corona G, Vignozzi L, et al. Metabolic syndrome and benign prostatic enlargement: a systematic reviewand meta-analysis BJU Int. 2015; 115:24-31.

16. Mirone V, Carone R, Carrieri G, et al. Urinary symptoms and sexual dysfunction among Italian men: The results of the \#Controllati survey.Arch Ital Urol Androl. 2017; 89:75-80.

17. Vuichoud C, Loughlin KR. Benign prostatic hyperplasia: epidemiology, economics and evaluation. Can J Urol. 2015; 22 Suppl $1: 1-6$.

18. Passi surveillance http://www.epicentro.iss.it/passi/dati/cardiovascolare.asp, last access November $17^{\text {th }} 2017$.

\section{Correspondence}

Vincenzo Mirone, MD

Università degli Studi di Napoli Federico II, UOC di Urologia della A.O.U. Federico II Napoli, Italy

Giuseppe Carrieri, MD

Dipartimento Nefro/Urologico Clinica Urologica e Centro Trapianti di rene, Università degli Studi di Foggia, Foggia, Italy

Giuseppe Morgia, MD

Università degli Studi di Catania Presidio Ospedaliero Policlinico, Catania, Italy

Luca Carmignani, MD

Università degli Studi di Milano, Divisione Universitaria di Urologia, IRCCS Policlinico San Donato Milano, Italy

Giuseppe Vespasiani, MD

UOC Urologia, Fondazione PTV - Policlinico Tor Vergata, Roma, Italy

Fabio Parazzini, MD (Corresponding Author)

Università degli Studi di Milano Dipartimento di Scienze Cliniche e di Comunità, IRCCS Policlinico, Milano, Italy fabio.parazzini@unimi.it

Walter Artibani, MD

Azienda Ospedaliera Universitaria Integrata Verona, Italy

*The Controllati\# study group:

Abano Terme, Policlinico: A. Porreca;

Acireale, P.O. S. Marta e S. Venera di Acireale Azienda Sanitaria Provinciale di Catania: A.

Ingrassia;

Acquaviva delle Fonti, Ente Ecclesiastico Ospedale Generale Regionale F. Miulli: G.M. Ludovico; Adria, Ospedale di Adria, ULSS5 Polesana: A. Meneghini;

Agrigento, Ospedale San Giovanni di Dio: M. Ruppolo;

Alba, Ospedale San Lazzaro: G. Fasolis;

Altamura, Ospedale della Murgia Fabio Perinei: M. De Siati;

Ancona, Ospedali Riuniti: A.B. Galosi;

Andria, ASL BAT P.O. L. Bonomo: A. Corvasce;

Arezzo, Ospedale San Donato: M. De Angelis;

Avellino, Azienda Ospedaliera S. Giuseppe Moscati: V. Cicalese;

Avellino, Casa di Cura Villa Esther: M. Di Martino;

Baggiovara, Nuovo Ospedale Civile Sant'Agostino Estense: A. Mofferdin;

Bari, Azienda Ospedaliera Policlinico di Bari - U.O. Urologia Universitaria 1: M. Battaglia;

Bari, Azienda Ospedaliera Policlinico di Bari - U.O. Urologia Universitaria 2: P Ditonno;

Bassano del Grappa, Ospedale Civile: A. Celia;

Benevento, AO Gaetano Rummo: L. Salzano;

Benevento, Casa di Cura Nuova Clinica Santa Rita: M. Coscione;

Bergamo, Casa di Cura Palazzolo, P. Belvisi:

Bologna, Azienda Ospedaliero - Universitaria di Bologna - Policlinico S. Orsola: E. Brunocilla;

Borgomanero Ospedale SS Trinità: G. Monesi;

Borgosesia, Ospedale S.S. Pietro e Paolo: G. Cipollone;

Brescia, Presidio Ospedaliero: C. Simeone;

Brindisi, Presidio Di Summa-Perrino: S. Brigante;

Bussolengo, Ospedale ORLANDI di Bussolengo - UOC urologia AULSS 9 - Veneto: G. Pecoraro;

Cagliari Ospedale SS Trinità: A. De Lisa;

Campi Bisenzio, Ambulatori della Misericordia: F. Lunghi;

Carpi, Ospedale Civile Ramazzini: M. Brausi;

Casarano,Ospedale Ferrari: S. Raguso;

Caserta, Azienda Ospedaliera Sant Anna e San Sebastiano di Caserta: S. Caggiano;

Castelfranco Veneto, Ospedale San Giacomo Apostolo: L. De Zorzi;

Castellammare di Stabia, Casa di Cura Villa Stabia:G. Scognamiglio;

Castiglione del lago, Ospedale Civile: F. Balloni;

Catania, Casa di Cura Gibiino: C. Ranno;

Catania, Ospedale Garibaldi Nesima: P.G. La Rosa;
Catania, Ospedale Vittorio Emanuele II: M. Falsaperla;

Catania, Policlinico Gaspare Rodolico Clinica Urologica - Università di Catania: G. Morgia

Catanzaro, Azienda Ospedaliera Universitaria Mater Domini: R. Damiano;

Cesano Boscone, Casa di Cura Ambrosiana: F.Catanzaro;

Chiari, ASST Franciacorta - Ospedale M. Mellini: L. Tralce;

Chieti, Policlinico SS. Annunziata: L. Schips;

Chieti, Università degli Studi Gabriele D'Annunzio: R. Tenaglia;

Chieti, Villa Pini d'Abruzzo: G. Marascia;

Città di Castello, Ospedale Civile: F. Balloni

Città Sant'Angelo, Villa Serena: R. D'Andrea;

Civitanova Marche, Ospedale Civile: E. Caraceni;

Cosenza, Ospedale Civile P.O. Dell'Annunziata: F. Ventura;

Cremona, Azienda Socio-Sanitaria Territoriale: C. Del Boca;

Domodossola, Ospedale San Biagio: A. Rosa;

Eboli, Ospedale Maria SS. Addolorata: A. Tufano:

Enna, Azienda Sanitaria Provinciale 4 Enna - P.O. Umberto I: M. D’Anca;

Fano, Azienda Ospedali Riuniti Marche Nord - Presidio Santa Croce di Fano: V. Beatrici;

Feltre, Ospedale S. Maria del Prato- ULSS2: D. Xausa;

Firenze, Ospedale AOU-Careggi: M. Carini, S. Serni;

Foggia, Ospedali Riuniti: G. Carrieri;

Foligno, Ospedale San Giovanni Battista: S. Parziani;

Forli, Ospedale G.B. Morgagni-Pierantoni: R. Gunelli;

Frascati, Ospedale San Sebastiano: F. Carbonaro;

Gallico- Reggio Calabria, ASL-Struttura Poliambulatoriale: M. De Martin

Garbagnate Milanese, Ospedale Guido Salvini - Urologia 1: A. Gregori;

Gela, Ospedale Vittorio Emanuele: N. Condorelli;

Genova, Clinica Urologica dell'Azienda Ospedaliero Universitaria San Martino: C. Terrone;

Genova, Ente Ospedaliero - Ospedali Galliera: C. Introini;

Gravina di Catania, Casa di Cura Musumeci Gecas: R. Leonardi;

Guastalla, Ospedale Civile: A. Frattini;

Isola della Scala, Ospedale Civile: G. Pecoraro;

Jesi, Ospedale Carlo Urbani: V. Ferrara;

L'Aquila, Ospedale S. Salvatore: L. Di Clemente;

Lanciano, Ospedale Floraspe Renzetti: L. Schips;

Latina, Ospedale ICOT: A. Carbone;

Lecce, ASL Vito Fazzi: A. Filoni

Lido di Camaiore, Ospedale Versilia-USL 12 Toscana Nord Ovest: M Cecchi; 
Locri Ospedale Spoke: A. Verbena;

Lovere Ospedale SS Capitanio e Gerosa: A Ranieri;

Lucca, Nuovo ospedale San Luca - USL Nord-Ovest: G. Santelli;

Magenta, Ospedale Civile: S. Sandri;

Mantova, Ospedale Poma: B. Dall'Oglio;

Messina, Azienda Ospedaliera Universitaria Policlinico G. Martino: V. Ficarra:

Messina, Casa di Cura S. Camillo: S. Bruschetta;

Messina, Ospedali Riuniti Papardo Piemonte: F. Mastroeni;

Milano, Azienda Socio Sanitaria Santi Paolo e Carlo: G. Dormia;

Milano, ASST Grande Ospedale Metropolitano Niguarda: A. Bocciardi

Milano, Fondazione Ca' Granda - I.R.C.C.S. - Ospedale Maggiore - Policlinico: E. Montanari;

Milano, Humanitas-San Pio X: L. Nava;

Milano, Istituto Europeo di Oncologia: O. De Cobelli;

Milano, Ospedale S. Raffaele: F. Montorsi;

Mirabella Eclano, Casa di Cura Villa Maria: E. Morelli;

Modena, Hesperia Hospital: G. Ferrari;

Modena, OCSAE - Nuovo Ospedale Civile Sant'Agostino Estense: G. Bianchi;

Molfetta, Ospedale Don Tonino Bello: M. Altomare;

Mondragone, Clinica Padre Pio: G.S. Sepe;

Monopoli, Ospedale Civile S. Giacomo: V. Recapito;

Montepulciano, Stabilimento Ospedaliero Nottola: G. Oliva;

Napoli, Azienda Ospedaliera Universitaria - Seconda Università degli Studi: M. De Sio;

Napoli, Istituto Nazionale Tumori IRCCS Fondazione Pascale: S. Perdonà;

Napoli, Ospedale Buon Consiglio Fatebenefratelli: V. Imperatore;

Napoli, Ospedale Cardarelli: P. Fedelini;

Napoli, Ospedale Cardinale Ascalesi: A.R. Zito;

Napoli, Ospedale Vincenzo Monaldi: F. Uricchio

Napoli, Policlinico Federico II: V.G. Mirone;

Negrar, Ospedale Sacro Cuore: S. Cavalleri;

Nocera Inferiore, P:O: Umberto I: R. Sanseverino;

Novara, Azienda Ospedaliero Universitaria Maggiore della Carità : A. Volpe;

Novi Ligure, Ospedale San Giacomo - ASL 22: F. Montefiore;

Nuoro, Ospedale San Francesco: F.M. Cossu;

Orbassano, Azienda Ospedaliero-Universitaria S. Luigi Gonzaga: F. Porpiglia;

Ottaviano, Casa di Cura Trusso: G. De Stefano;

Padova, Azienda Ospedaliera: F. Zattoni;

Padova, Centro Poliambulatorio ai Colli: M. Dal Bianco;

Palermo, Azienda Universitaria Ospedaliera Policlinico Paolo Giaccone: A. Simonato; Parma, AOU: U.V. Maestroni;

Perugia, Ospedale S. Maria della Misericordia - S. Andrea delle Fratte: E. Mearini;

Pescara, Clinica Pierangeli: P. Pompa

Pescara, Presidio Ospedaliero: R. Renzetti;

Peschiera del Garda, Casa di Cura Pederzoli: G. Grosso;

Piacenza, Ospedale Guglielmo da Saliceto: I.M. Tavolini

Pisa, Azienda Ospedaliero Universitaria Pisana - Stabilimento di Cisanello: C. Selli;

Polla, Presidio Ospedaliero di Polla-ASL Salerno: D. Rubino;

Ponderano, Ospedale degli Infermi - ASL Biella: S. Zaramella;

Pordenone, AIED: S. Bucci

Pozzuoli, Ospedale Santa Maria delle Grazie: G. Di Lauro;

Prato, Ospedale Misericordia e Dolce: F. Blefari;
Ragusa, Ospedale Civile, F. Curto

Ravenna, Ospedale S. Maria delle Croci: S. Voce;

Reggio Calabria, ASL 11 Struttura Nord: M. De Martin;

Rimini, Ospedale degli Infermi: F. Montanari;

Rocca di Neto: F. Greco:

Roma, Aurelia Hospital: R. Cusumano;

Roma, Azienda ospedaliera Sant'Andrea: A. Tubaro;

Roma, Casa di Cura Nuova Villa Claudia: R. Giulianelli;

Roma, Clinica Fabia Mater: M. Cappa;

Roma, Complesso Integrato Columbus: A. D’Addessi;

Roma, Fondazione PTV Policlinico - Tor Vergata: G. Vespasiani;

Roma, Ospedale di Zona Cristo Re: L. Defidio

Roma, Ospedale S. Carlo Forlanini: C. Anceschi;

Roma, Ospedale S. Filippo Neri: G. Sampalmieri;

Roma, Policlinico A. Gemelli: P. Bassi:

Roma, Policlinico Umberto I: C. De Dominicis;

Roma, Policlinico Universitario Campus Bio-Medico: G. Muto;

Salerno, AOU S. Giovanni di Dio R. d'Aragona: U. Greco;

San Bonifacio; Ospedale Fracastoro: C.Tallarigo;

San Cataldo, Casa di Cura Regina Pacis:C. Cammarata;

San Donà di Piave, Casa di Cura Sileno ed Anna Rizzola: G. Loiero;

San Donato Milanese, Ospedale Clinicizzato S. Donato: L.F. Carmignani;

San Giovanni Rotondo, Ospedale Casa Sollievo della Sofferenza: A. Cisternino;

Santa Maria Capua Vetere, Clinica S. Maria della Salute: M. Sorrentino;

Sarzana, Ospedale San Bartolomeo: E. Conti;

Sassari, Azienda Ospedaliero-Universitaria: M. Madonia

Senigallia, Ospedale Principe di Piemonte: A. Cavicchi,

Sestri Levante, ASL4- Chiavarese: M. Medica;

Siena,AOUS Ospedale S. Maria delle Scotte: G. Barbanti;

Siracusa, Azienda Ospedaliera Umberto I: B. Lentini,

Sondrio, Ospedale di Sondrio - Azienda Ospedaliera di Valtellina e Valchiavenna: P. Piras;

Taranto Ospedale Ss Annunziata: F Beleggia;

Teramo, Ospedale Mazzini: C. Vicentini;

Termoli, Ospedale San Timoteo: G. Di Monaco;

Terni, Azienda Ospedaliera Santa Maria: E. Mearini;

Tivoli, Ospedale S. Giovanni Evangelista: A. Laganà:

Trento, Ospedale Santa Chiara: G. Malossini;

Treviglio, Ospedale di Treviglio-Caravaggio-ASST BG Ovest: O. Risi;

Torino, Città della Salute e della Scienza-Ospedale Molinette: P. Gontero;

Torino, Ospedale Cottolengo: C.M. Scoffone;

Torino, Ospedale San Giovanni Bosco Castelli di Torino - SC Urologia 2: E. Castelli;

Torino, Presidio Ospedaliero CTO - Unità Spinale Struttura Complessa di Neuro Urologia: R. Carone;

Udine, AIED: S. Ciciliato;

Vallo della Lucania, Casa di Cura Luigi Cobellis: A. Cavaliere;

Varese, Ospedale di Circolo Fondazione Macchi: A.M. Marconi;

Vasto, Ospedale San Pio da Pietrelcina: L.Schips;

Vercelli, Ospedale S. Andrea: G. Cipollone;

Verona, Azienda Ospedaliera-Universitaria Integrata - Ospedale Borgo Trento: W. Artibani;

Viterbo, Ospedale di Belcolle: A. Rizzotto;

Voghera, Azienda Socio Sanitaria Territoriale di Pavia - Ospedale Civile: M. Mensi. 